\title{
Mesoporous Magnesium Oxide Nanosheets Electrocatalysts for the Detection of Lead(II)
}

\author{
Sen Liu,${ }^{\dagger}$ Ziying Wang, ${ }^{\dagger}$ Tianyi Han,${ }^{\dagger}$ Teng Fei, ${ }^{\dagger, \dagger}$ and Tong Zhang ${ }^{*}, \dagger$
}

†State Key Laboratory on Integrated Optoelectronics, College of Electronic Science and Engineering, Jilin University, Changchun 130012, P. R. China and ¥State Key Laboratory of Transducer Technology, Shanghai 200050, P. R. China

*Corresponding author. E-mail: zhangtong@jlu.edu.cn

\section{Experimental section}

\section{Materials}

$\mathrm{Mg}\left(\mathrm{NO}_{3}\right)_{2} \cdot 6 \mathrm{H}_{2} \mathrm{O}$, glucose $\cdot \mathrm{H}_{2} \mathrm{O}, \quad \mathrm{Pb}\left(\mathrm{NO}_{3}\right)_{2} \cdot \quad \mathrm{Hg}\left(\mathrm{NO}_{3}\right)_{2} \cdot 0.5 \mathrm{H}_{2} \mathrm{O}, \quad \mathrm{Cd}\left(\mathrm{NO}_{3}\right)_{2} \cdot 4 \mathrm{H}_{2} \mathrm{O}$, $\mathrm{Cr}\left(\mathrm{NO}_{3}\right)_{3} \cdot 9 \mathrm{H}_{2} \mathrm{O}, \mathrm{Zn}\left(\mathrm{NO}_{3}\right)_{2} \cdot 6 \mathrm{H}_{2} \mathrm{O}$, sodium acetate and acetic acid (purchased from Aladdin) are used without further purification. $\mathrm{Pb}(\mathrm{II})$ and other metal ions were prepared daily. The deionized water used throughout all experiments was purified through a Millipore system. The $0.1 \mathrm{M}$ acetate buffer solution of $\mathrm{pH} 5.0$ was prepared with sodium acetate and acetic acid as the supporting electrolyte.

\section{Methods}

Synthesis of MgO-NSs: MgO-NSs were synthesized by direct calcination of $\mathrm{Mg}\left(\mathrm{NO}_{3}\right)_{2}$-glucose mixture. In a typical process, $1.25 \mathrm{~g}$ of $\mathrm{Mg}\left(\mathrm{NO}_{3}\right)_{2} \cdot 6 \mathrm{H}_{2} \mathrm{O}$ and 1.80 g of glucose $\cdot \mathrm{H}_{2} \mathrm{O}$ were added into $25 \mathrm{~mL}$ of water in a $150-\mathrm{mL}$ quartz breaker. After dissolution of the precursors in water, the breaker was transferred into an oven and 
heated at $100{ }^{\circ} \mathrm{C}$ until the water was removed completely. Then, the breaker containing precursors was thermal treatment at $550{ }^{\circ} \mathrm{C}$ for $3 \mathrm{~h}$ in a muffle furnace to remove glucose. Finally, 2D MgO-NSs were obtained. Other MgO-NSs samples were also prepared through the same process, just changing the amount of glucose $\cdot \mathrm{H}_{2} \mathrm{O}$ to $0.90 \mathrm{~g}, 2.70 \mathrm{~g}$ and $3.60 \mathrm{~g}$, respectively.

Additionally, conventional $\mathrm{MgO}$ samples were synthesized by the similar method in the absence of glucose, where the samples were designated with MgO-MPs.

\section{Construction of electrochemical sensors}

The construction of the MgO-NSs/Nafion film on the surface of glassy carbon electrode (GCE) was performed as follows: original 5\% w/w Nafion solution was diluted to $0.5 \% \mathrm{w} / \mathrm{w}$ solution with water. Then $\mathrm{MgO}-\mathrm{NSs}(10 \mathrm{mg})$ were dissolved in 1 $\mathrm{mL}$ of the above solution and sonicated for $30 \mathrm{~min}$ to get a homogeneous MgO-NSs/Nafion suspension. A $3 \mu \mathrm{L}$ aliquot of this suspension was then dropped onto the surface of a freshly polished GCE, followed by dryness at room temperature.

\section{Characterization}

The morphology of MgO-NSs was characterized with a scanning electron microscopy (6700F, JEOL). The structure of MgO-NSs was observed by transmission electron microscopy (TEM) on a HITACHI H-8100 electron microscopy (Hitachi, Japan) with an accelerating voltage of $200 \mathrm{kV}$. Powder X-ray diffraction (XRD) data were recorded on a RigakuD/MAX 2550 diffractometer with $\mathrm{Cu}-\mathrm{K} \alpha$ radiation $(\lambda=1.5418$ Å). X-ray photoelectron spectroscopy (XPS) analysis was measured on an ESCALAB MK II X-ray photoelectron spectrometer using Mg as the exciting source. 
Electrochemical measurements were recorded with a CHI 660D computer-controlled potentiostat (ChenHua Instruments Co., Shanghai, China) with a standard three-electrode system. A modified GCE (geometric area $=0.07 \mathrm{~cm}^{2}$ ) served as working electrode, a saturated $\mathrm{Ag} / \mathrm{AgCl}$ electrode as the reference-electrode, and a platinum wire was used as a counter-electrode. All the experiments were carried out at room temperature.

\section{$\mathrm{Pb}(\mathrm{II})$ detection}

Square wave anodic stripping voltammetry (SWASV) was used for the $\mathrm{Pb}$ (II) detection under optimized conditions. Lead was deposited at the potential of $-1.2 \mathrm{~V}$ for $900 \mathrm{~s}$ by the reduction of $\mathrm{Pb}(\mathrm{II})$ ion in $0.1 \mathrm{M} \mathrm{NaAc}-\mathrm{HAc}$. The anodic stripping (reoxidation of metal to metal ions) of the electrodeposited metal was performed in the potential range of -0.9 to $-0.2 \mathrm{~V}$ at the following parameters: frequency, $15 \mathrm{~Hz}$; amplitude, $25 \mathrm{mV}$. 


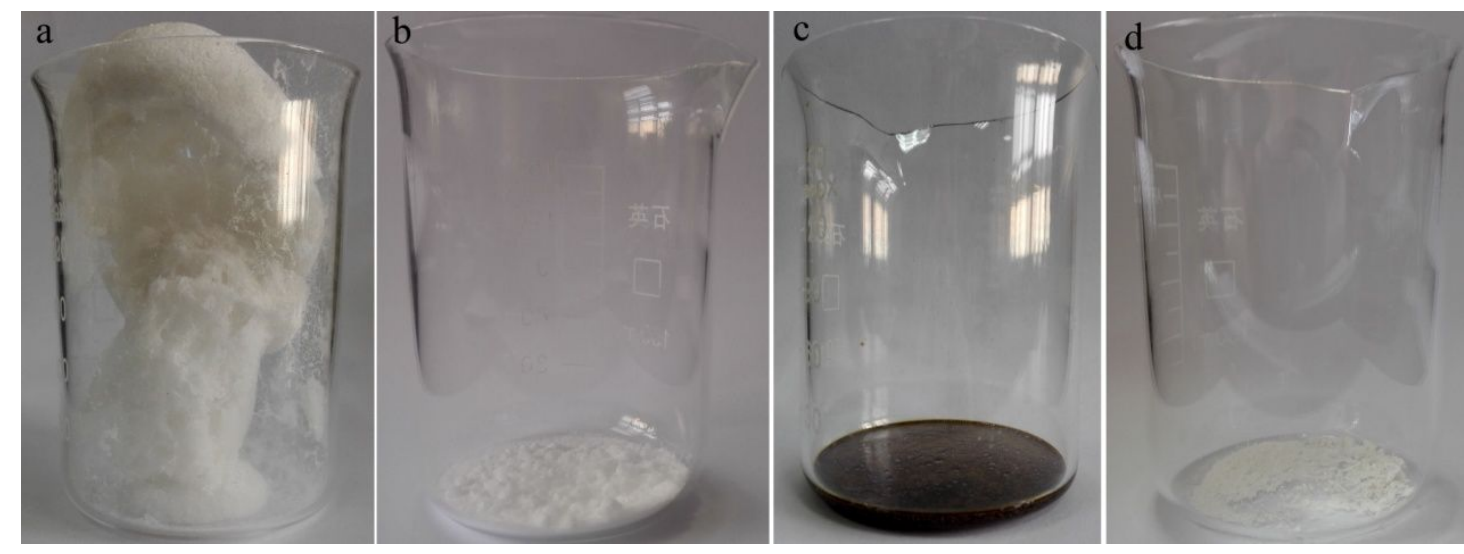

Figure S1 The photographs of the various solid samples: (a) MgO-NSs prepared our proposed facile method by calcination of $1.25 \mathrm{~g}$ of $\mathrm{Mg}\left(\mathrm{NO}_{3}\right)_{2} \cdot 6 \mathrm{H}_{2} \mathrm{O}$ and $1.80 \mathrm{~g}$ of glucose $\cdot \mathrm{H}_{2} \mathrm{O}$, (b) the mixture of $1.25 \mathrm{~g}$ of $\mathrm{Mg}\left(\mathrm{NO}_{3}\right)_{2} \cdot 6 \mathrm{H}_{2} \mathrm{O}$ and $1.80 \mathrm{~g}$ of glucose $\cdot \mathrm{H}_{2} \mathrm{O}$, (c) the solid powder before calcination from $1.25 \mathrm{~g}$ of $\mathrm{Mg}\left(\mathrm{NO}_{3}\right)_{2} \cdot 6 \mathrm{H}_{2} \mathrm{O}$ and $1.80 \mathrm{~g}$ of glucose $\cdot \mathrm{H}_{2} \mathrm{O}$, and (d) MgO-MPs obtained by calcination of $1.25 \mathrm{~g}$ of $\mathrm{Mg}\left(\mathrm{NO}_{3}\right)_{2} \cdot 6 \mathrm{H}_{2} \mathrm{O}$. 


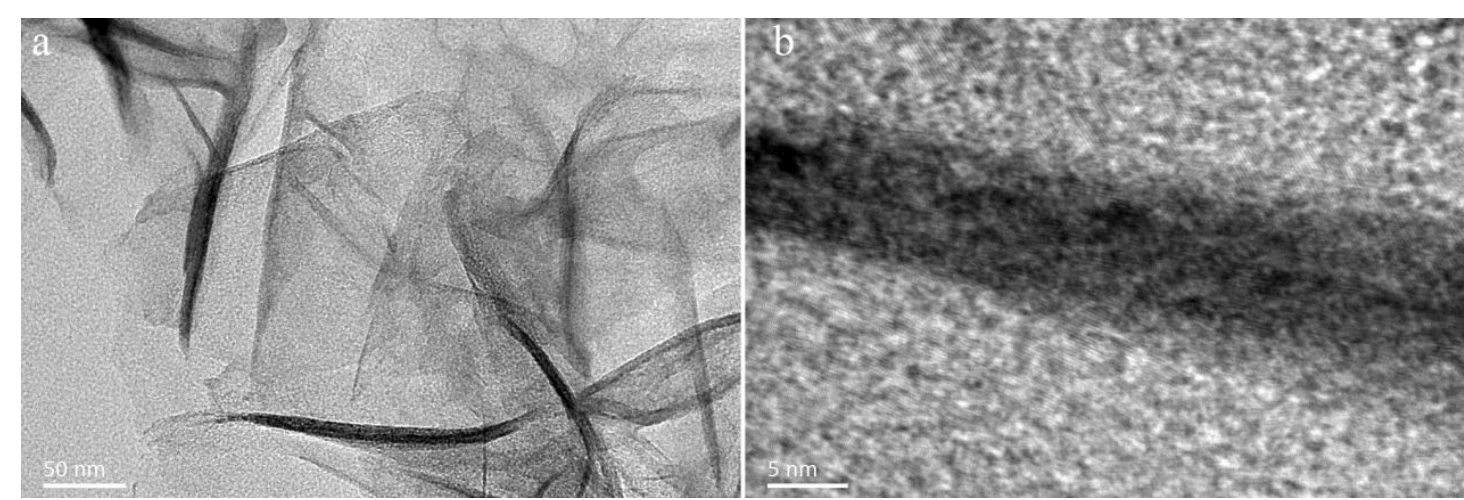

Figure S2 (a) Low and (b) high magnification TEM images of the overlap region for MgO-NSs. 


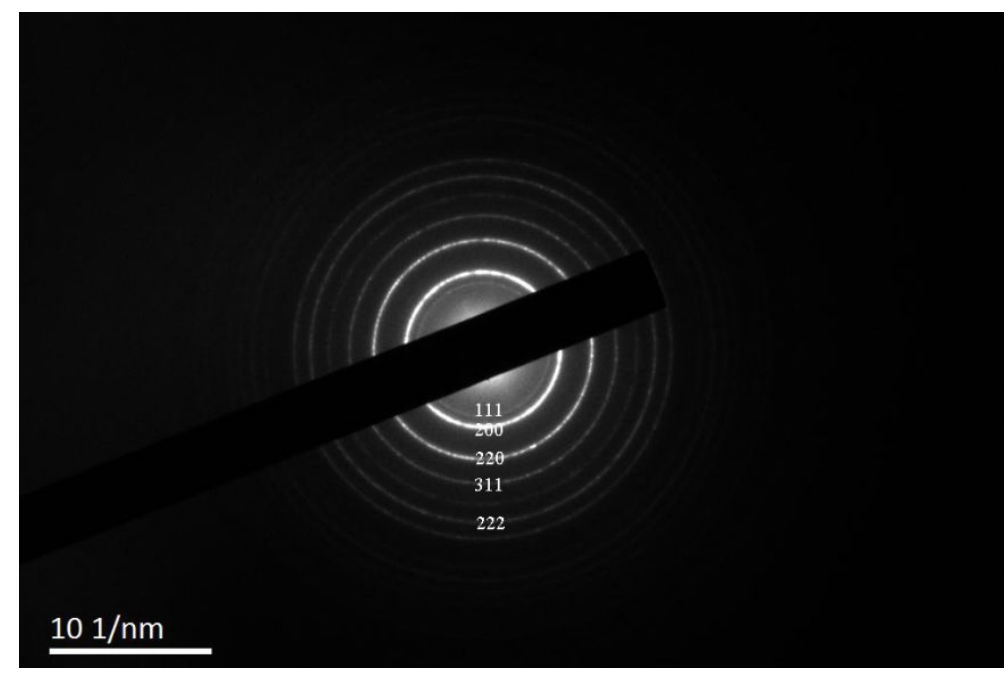

Figure S3 SAED image of MgO-NSs. 


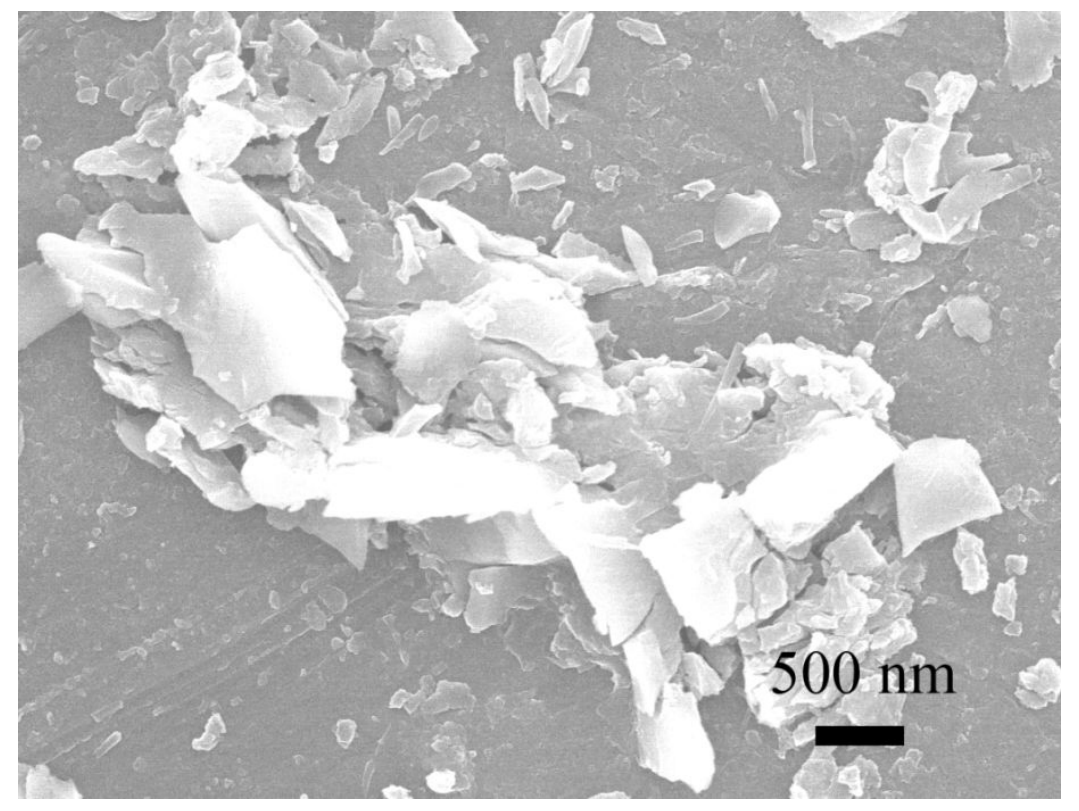

Figure S4 The SEM image of MgO-MPs prepared in the absence of glucose. 


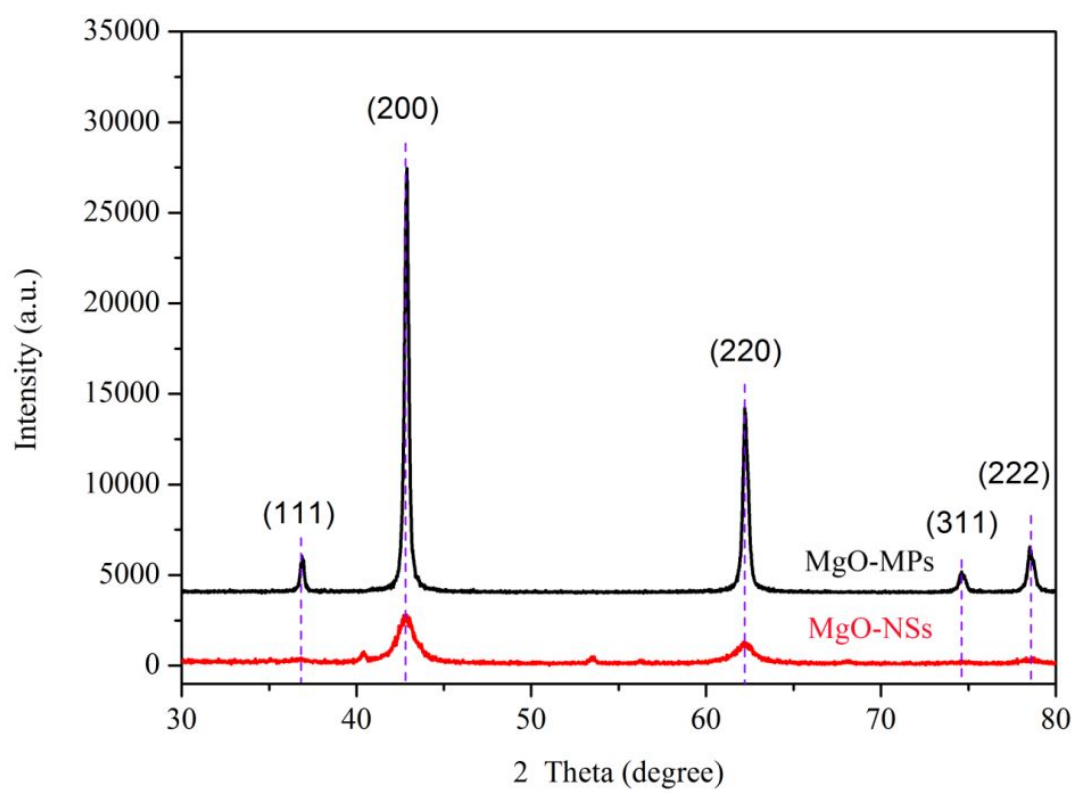

Figure S5 The XRD patterns of (a) MgO-NSs prepared by calcination of $1.25 \mathrm{~g}$ of $\mathrm{Mg}\left(\mathrm{NO}_{3}\right)_{2} \cdot 6 \mathrm{H}_{2} \mathrm{O}$ and $1.80 \mathrm{~g}$ of glucose $\cdot \mathrm{H}_{2} \mathrm{O}$, (b) MgO-MPs by calcination of $1.25 \mathrm{~g}$ of $\mathrm{Mg}\left(\mathrm{NO}_{3}\right)_{2} \cdot 6 \mathrm{H}_{2} \mathrm{O}$ in the absence of glucose. 


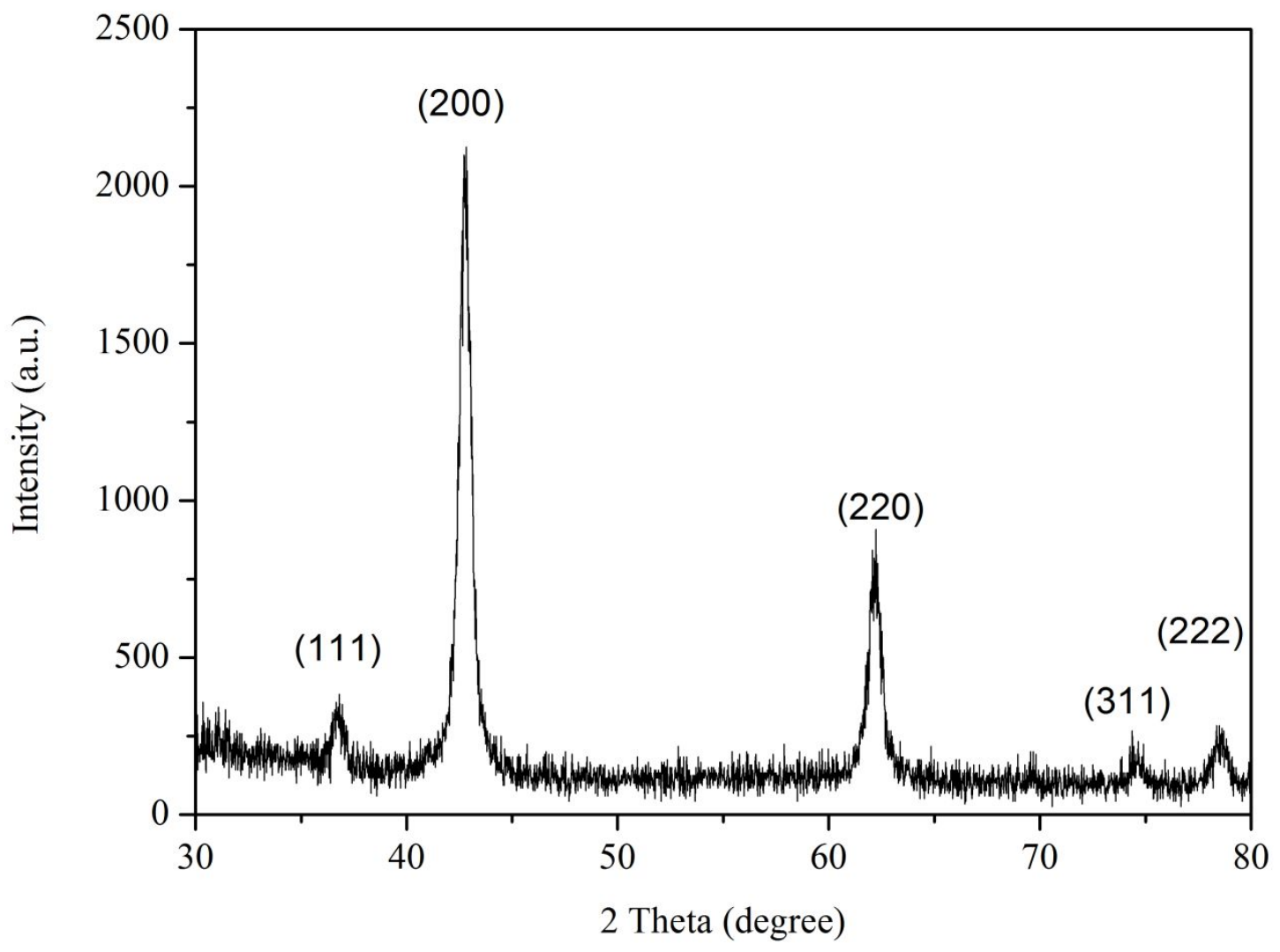

Figure S6 The XRD pattern of MgO-NSs prepared by calcination of $1.25 \mathrm{~g}$ of $\mathrm{Mg}\left(\mathrm{NO}_{3}\right)_{2} \cdot 6 \mathrm{H}_{2} \mathrm{O}$ and $1.80 \mathrm{~g}$ of glucose $\cdot \mathrm{H}_{2} \mathrm{O}$ after further calcination at $550{ }^{\circ} \mathrm{C}$ for $3 \mathrm{~h}$. 

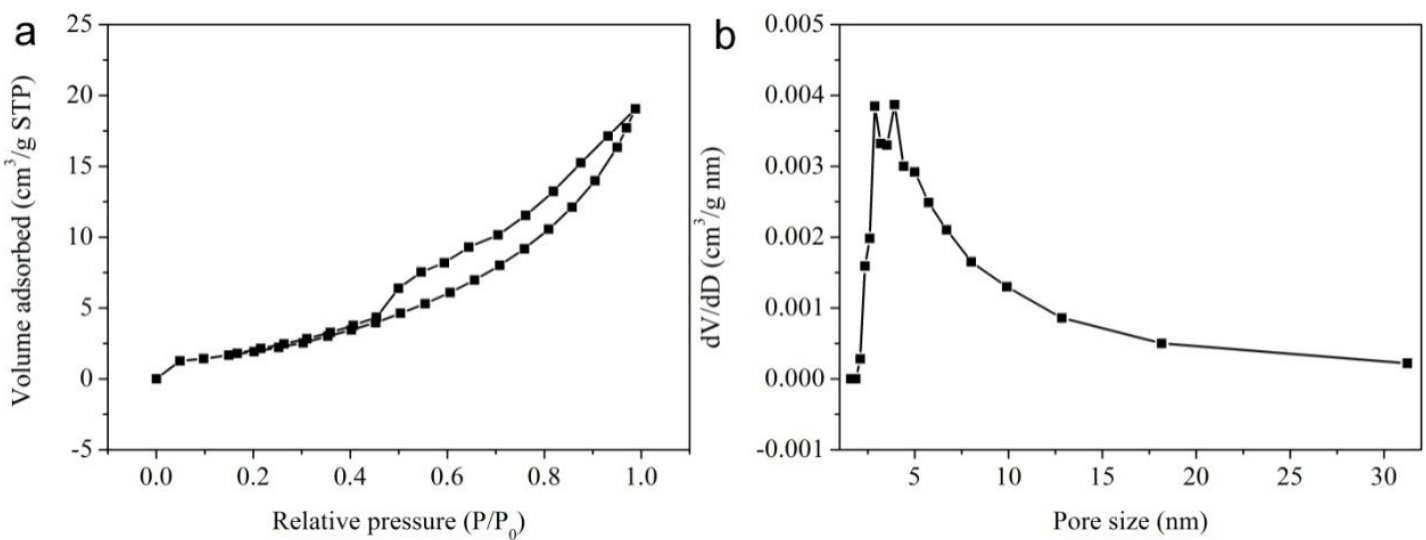

Figure $\mathbf{S 7}$ (a) $\mathrm{N}_{2}$ sorption isotherm and (b) BJH pore size distribution curve of MgO-MPs. 


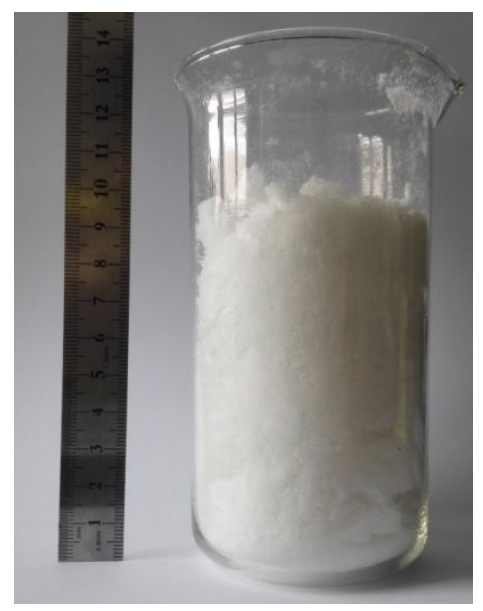

Figure S8 The photograph of $\mathrm{MgO}-\mathrm{NSs}$ prepared our proposed facile method by calcination of $2.50 \mathrm{~g}$ of $\mathrm{Mg}\left(\mathrm{NO}_{3}\right)_{2} \cdot 6 \mathrm{H}_{2} \mathrm{O}$ and $3.60 \mathrm{~g}$ of glucose $\cdot \mathrm{H}_{2} \mathrm{O}$. 

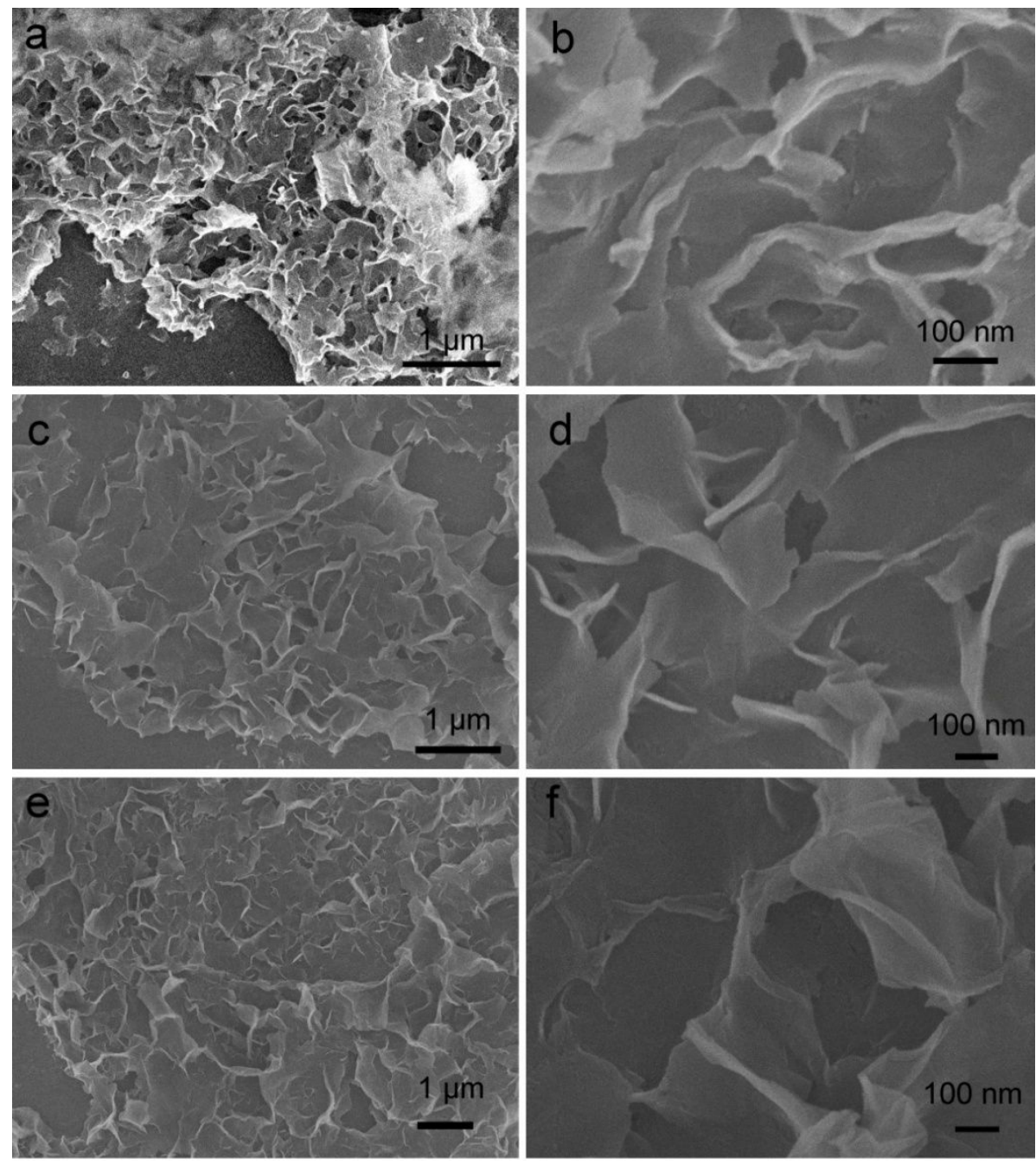

Figure S9 SEM images of (a, b) MgO-NSs-0.9, (c, d) MgO-NSs-2.7, and (e, f)

MgO-NSs-3.6. 


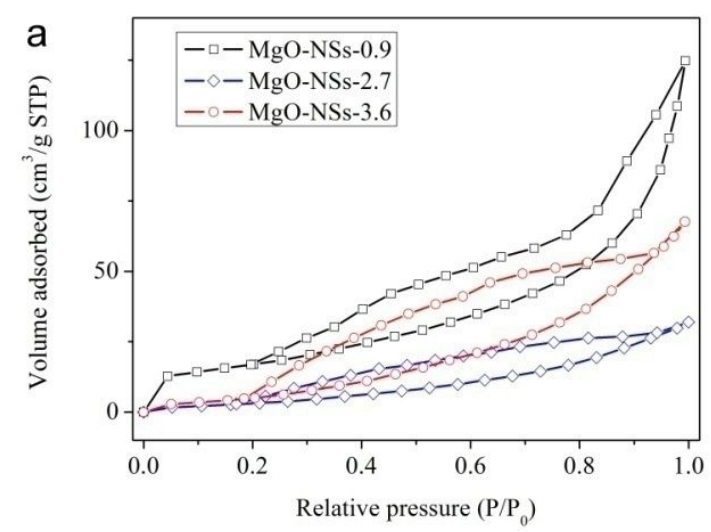

Figure S10 (a) $\mathrm{N}_{2}$ sorption isotherms and (b) BJH distribution curves of MgO-NSs-0.9, MgO-NSs-2.7, and MgO-NSs-3.6.

\section{Note 1:}

As shown in previous publications, the preparation of nanosheets-based materials by sugar-blowing methods is attributed to the unique sugar-blowing phenomenon of sugar under hearting. The formation of MgO-NSs could be attributed to the filling of Mg-precursors within the nanosheets derived from sugar-derived polymers. The mesostructure in $\mathrm{MgO}-\mathrm{NSs}$ is formed by $\mathrm{MgO}$ NPs separated by sugar-derived polymers, and thus the ratio of MgO NPs to sugar-derived polymers plays an important in mesoporous structure. When $0.9 \mathrm{~g}$ of glucose was added, few sugar-derived polymers can not separate $\mathrm{MgO}$ NPs well, leading to poor mesostructure. In contrast, if $2.7 \mathrm{~g}$ or $3.6 \mathrm{~g}$ of glucose was added into mixture, too much glucose-derived polymers were formed around MgO NPs, also resulting in poor mesoporous structure. It is deduced that the mass ratio of $\mathrm{Mg}$ salt to glucose at $1.25 \mathrm{~g}$ to $1.80 \mathrm{~g}$ may be the optimized condition for formation of $\mathrm{MgO}-\mathrm{NSs}$ with good mesoporous structure. The effect of glucose amount on the mesoporous structure in $\mathrm{MgO}-\mathrm{NSs}$ is the same to that for preparation of mesoporous silica or $\gamma-\mathrm{Al}_{2} \mathrm{O}_{3}$ 
templated by glucose. ${ }^{1-3}$ Therefore, the role of glucose in the synthesis of MgO-NSs could be concluded as following two aspects: Firstly, the sugar-blowing property of glucose ensures the formation of nanosheets without aggregating, which is obviously different from that for MgO-MPs. Secondly, the presence of sugar-derived polymers from glucose leadings to formation of separated $\mathrm{MgO}$ nanoparticles in the nanosheets. 

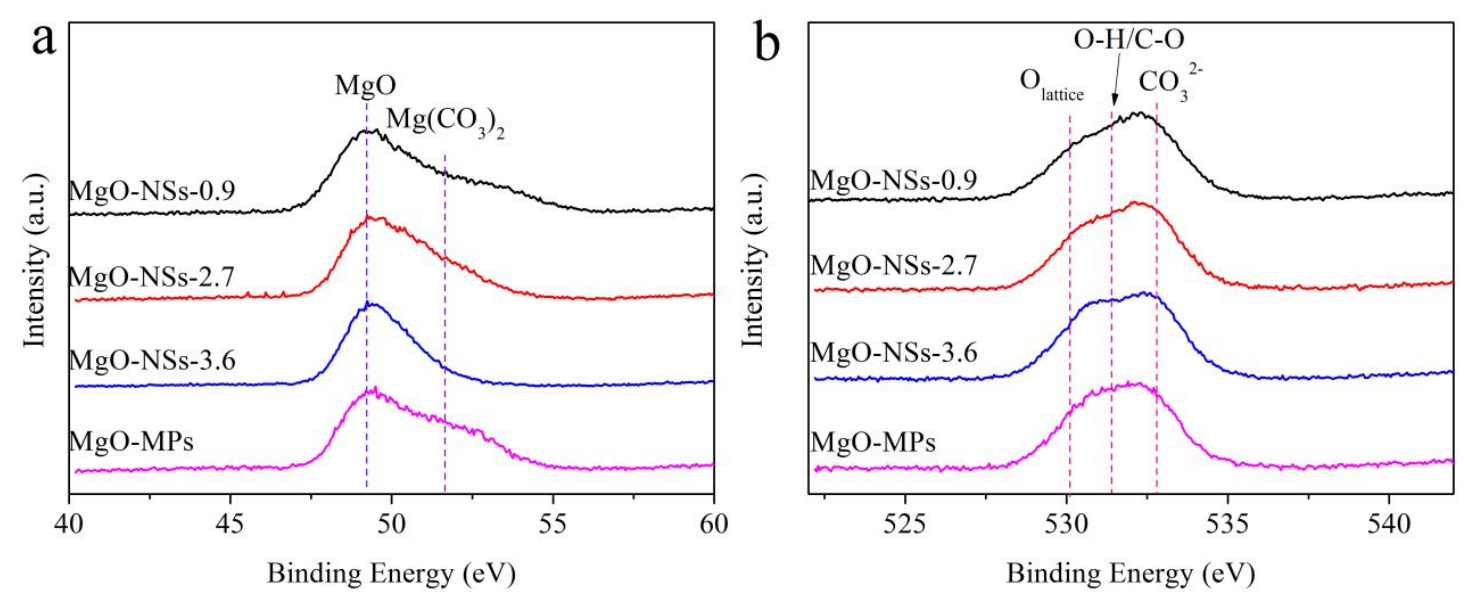

Figure $\mathrm{S11}$ (a) $\mathrm{Mg} 2 \mathrm{p}$ and (b) $\mathrm{O} 1 \mathrm{~s}$ spectra of MgO-NSs-0.9, MgO-NSs-2.7, MgO-NSs-3.6, and MgO-MPs.

\section{Note 2:}

Furthermore, the surface structure and chemical valence states for $\mathrm{MgO}$-based samples beyond $\mathrm{MgO}-\mathrm{NSs}$ were also examined, and corresponding $\mathrm{Mg} 2 \mathrm{p}$ and $\mathrm{O}$ 1s XPS spectra were shown in Figure S11. Normally, the $\mathrm{Mg} 2 \mathrm{P}$ spectrum is deconvoluted into two peaks centered at $49.35 \mathrm{eV}$ and $51.36 \mathrm{eV}$ attributed to the $\mathrm{Mg}(\mathrm{II})$ in $\mathrm{MgO}$ and $\mathrm{Mg}\left(\mathrm{CO}_{3}\right)_{2}$, respectively. ${ }^{4} \mathrm{Mg}$ 2p spectrum of $\mathrm{MgO}-\mathrm{MPs}$ indicating the existence of $\mathrm{MgO}$, along with small content of $\mathrm{Mg}\left(\mathrm{CO}_{3}\right)_{2}$, derived from the adsorption of $\mathrm{CO}_{2}$. When small amount of glucose $(0.9 \mathrm{~g})$ was added, a decrease of $\mathrm{Mg}\left(\mathrm{CO}_{3}\right)_{2}$ was observed for MgO-NSs-0.9. By increasing glucoses used (1.8 g, 2.7 $\mathrm{g}, 3.6 \mathrm{~g})$, the samples exhibit obscure $\mathrm{Mg}\left(\mathrm{CO}_{3}\right)_{2}$, which may be attributed to the increasing content of carbon residues from glucose. The $\mathrm{O}$ 1s spectrum in MgO-based materials is deconvoluted into three peaks centered at $530.1 \mathrm{eV}, 531.4 \mathrm{eV}$ and 532.8 $\mathrm{eV}$ associated with oxygen in $\mathrm{MgO}$ lattice, $\mathrm{C}-\mathrm{O} / \mathrm{O}-\mathrm{H}$ bands and oxygen in $\mathrm{Mg}\left(\mathrm{CO}_{3}\right)_{2}$, respectively. ${ }^{5}$ It is seen that $\mathrm{MgO}-\mathrm{NSs}$ samples exhibit relatively low content of 
oxygen in lattice, indicating the destruction of $\mathrm{MgO}$ crystals with increasing the amount of glucose, which may be attributed to the introduction of carbon into MgO-NSs. However, there are no much difference in $\mathrm{O}$ 1s spectra between $\mathrm{MgO}-\mathrm{NSs}$ samples, indicating the weak effect on glucose amount on the surface chemical valence states. 


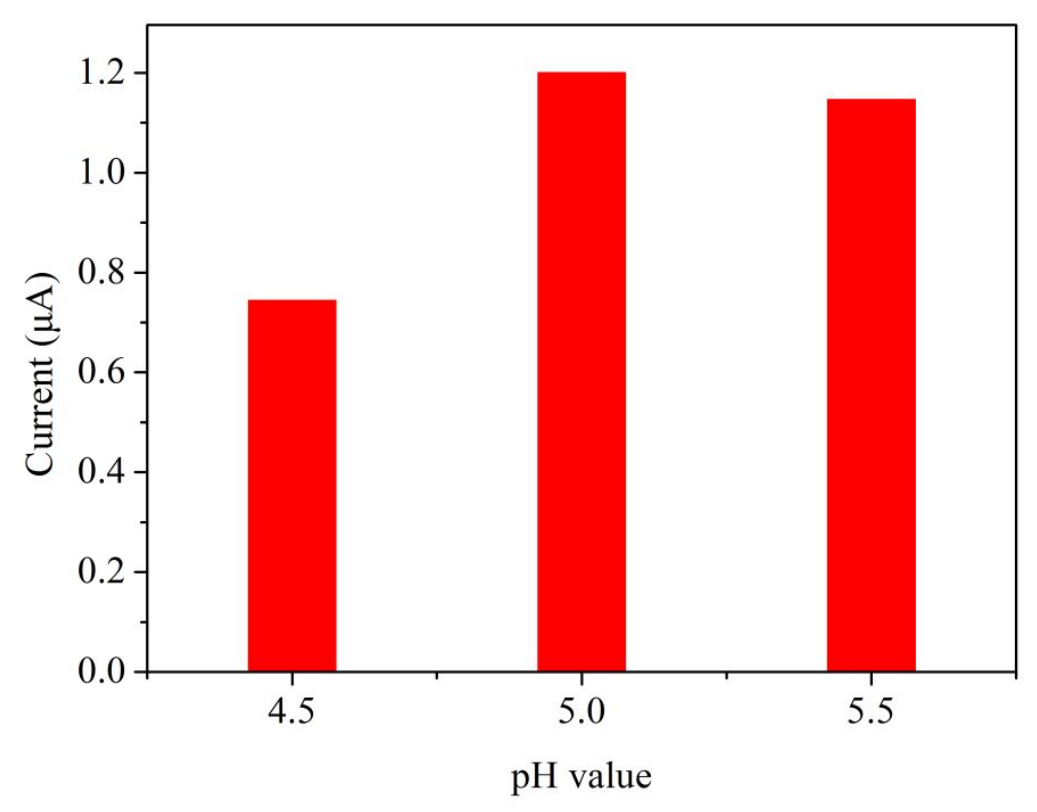

Figure S12 The current for oxidation of $\mathrm{Pb}(0)$ during square wave anodic stripping voltammetry (SWASV) curves of MgO-NSs/GCE in $0.1 \mathrm{M} \mathrm{NaAc-HAc}$ with the $\mathrm{pH}$ value of 4.5, 5.0 and 5.5, respectively.

\section{Note 3:}

The effect of the $\mathrm{pH}$ value on the response current for stripping of $\mathrm{Pb}^{0}$ during the SWASV process was also examined. As shown in Figure S12 (Supporting Information), the oxidation currents associated with oxidation of $\mathrm{Pb}(0)$ decrease with increasing $\mathrm{pH}$ value upto 5.5, or decreasing $\mathrm{pH}$ value to 4.5. The low oxidation current $\mathrm{Pb}(0)$ on $\mathrm{MgO}-\mathrm{NSs}$-based sensor in $\mathrm{pH} 4.5$ is attributed to the competitive binding of proton ions and $\mathrm{Pb}(\mathrm{II})$; While the low oxidation current $\mathrm{Pb}(0)$ on MgO-NSs-based sensor in $\mathrm{pH} 5.5$ is due to the hydrolysis of cations in water.

\section{Note 4:}

The overall sensing mechanism for electrochemcial detection $\mathrm{Pb}(\mathrm{II})$ based on MgO-NSs was proposed as follow possibly:

I. Adsorption and preconcentration: 
$(\mathrm{MgO}-\mathrm{NSs})_{\text {workingsurface }}+\left(\mathrm{Pb}^{2+}\right)_{\text {solution }}+2 e^{-} \rightarrow\left(\mathrm{Pb}^{0} \cdots \mathrm{MgO}-\mathrm{NSs}_{\text {workingsurface }}\right)$

Firstly, $\mathrm{Pb}(\mathrm{II})$ was adsorbed onto the surface of $\mathrm{MgO}-\mathrm{NSs}$, where the previous reports have revealed that the $\mathrm{MgO}$-based materials exhibit excellent adsorption capacitors toward inorganic anions. Secondly, after providing an applied potential of $-1.2 \mathrm{~V}, \mathrm{~Pb}(\mathrm{II})$ on the surface of $\mathrm{MgO}-\mathrm{NS}$ s was converted into $\mathrm{Pb}(0)$ during the accumulation process.

II. anodic stripping:

$$
\left(\mathrm{Pb}^{0} \cdots \mathrm{MgO}-\mathrm{NSs}_{\text {workingsurface }}\right) \rightarrow\left(\mathrm{Pb}^{2+}\right)_{\text {solution }}+(\mathrm{MgO}-\mathrm{NSs})_{\text {workingsurface }}+2 e^{-}
$$

By providing an applied potential ranging from $-0.70 \mathrm{~V}$ to $-0.30 \mathrm{~V}$, an anodic stripping reaction for oxidation of $\mathrm{Pb}(0)$ into $\mathrm{Pb}(\mathrm{II})$ was performed on the surface of MgO-NSs, along with the observation of oxidation peak centered at $-0.50 \mathrm{~V}$. 


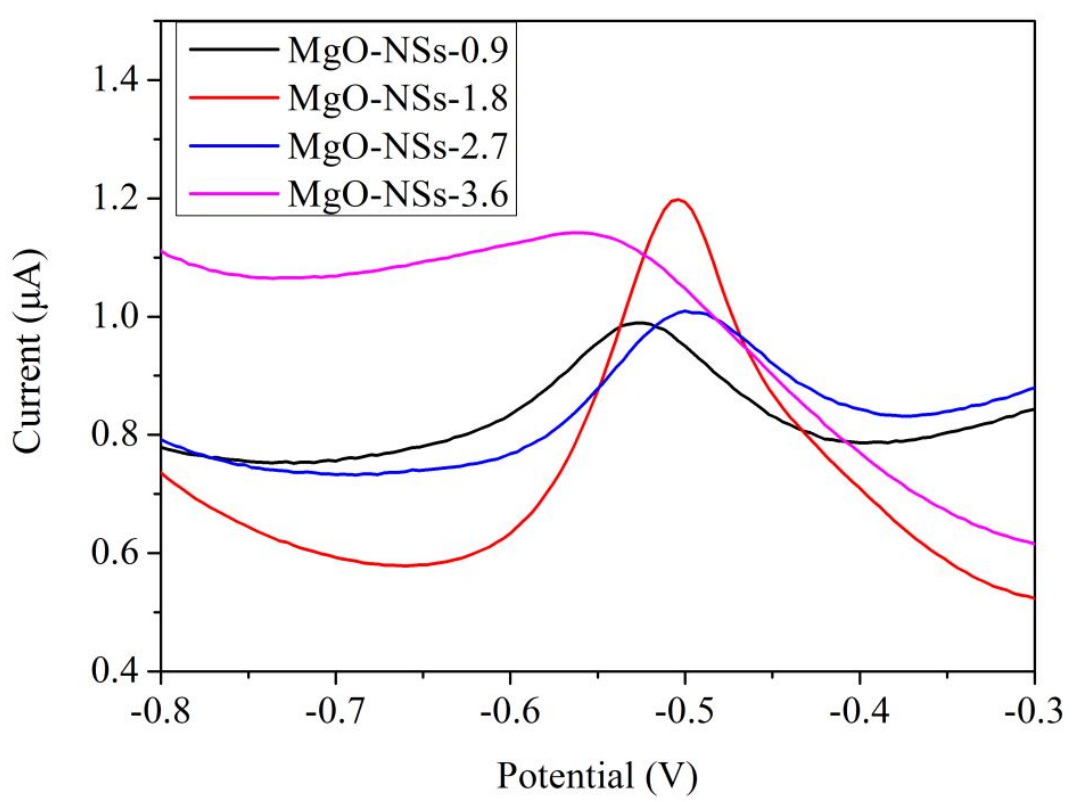

Figure S13 Square wave anodic stripping voltammetry (SWASV) curves of various MgO-NSs samples modified GCE in 0.1 M NaAc-HAc ( $\mathrm{pH} 5.0$ ) in the presence of 20 $\mathrm{nM} \mathrm{Pb}(\mathrm{II})$.

\section{Note 5:}

The previous results have shown that the content of glucose plays an important role in mesostrucutre of $\mathrm{MgO}-\mathrm{NSs}$ samples. Thus, the electrocatalytical activity of various MgO-NSs samples toward to $20 \mathrm{nM} \mathrm{Pb}$ (II) was also investigated and corresponding SWASV curves were shown in Figure S13 (Supporting Information). Notably, MgO-NSs-0.9 and MgO-NSs-2.7 exhibit much lower oxidation current toward $20 \mathrm{nM}$ $\mathrm{Pb}$ (II) than that of MgO-NSs-1.8. Although MgO-NSs-2.7 displays a slightly lower current compared to $\mathrm{MgO}-\mathrm{NSs}-1.8$, the high background current brings out poor sensing performances. 


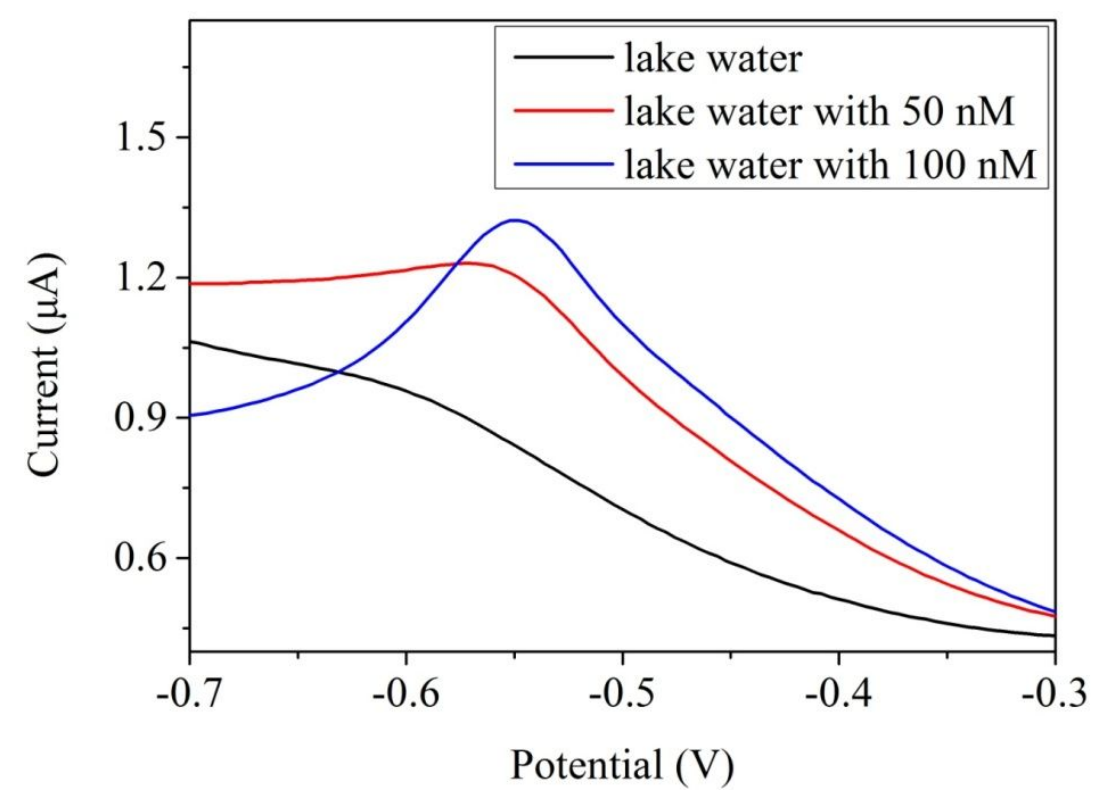

Figure S15 Square wave anodic stripping voltammetry (SWASV) curves of MgO-NSs/GCE in 0.1 M NaAc-HAc (pH 5.0) containing lake water (black line), lake water spiking with $50 \mathrm{nM} \mathrm{Pb}(\mathrm{II})$ (red line), and spiking with $100 \mathrm{nM} \mathrm{Pb}$ (II) (blue line).

\section{Note 6:}

For the purpose of practical application of the present sensor, a test of real water sample was further examined. The real sample was collected from Qing Lake in campus of Jilin University, Jilin Province, China, and the water was filtered using $0.45 \mu \mathrm{m}$ pore cellulose acetate membranes without further treatment. As shown in Figure S14 (Supporting Information), no stripping peak attributed to the oxidation of $\mathrm{Pb}(0)$ was observed by addition of lake water into the buffer, indicating that the $\mathrm{Pb}(\mathrm{II})$ concentration is below $20 \mathrm{nM}$. After addition of lake water with spiking $50 \mathrm{nM} \mathrm{Pb}(\mathrm{II})$, an obvious striping peak at $-0.56 \mathrm{~V}$ attributed to the oxidation of $\mathrm{Pb}(0)$ was observed. A further increase of the spiking concentration to $100 \mathrm{nM}$ results in the enhanced 
striping peak (Figure S14, Supporting Information). All these observations suggested that the present $\mathrm{MgO}-\mathrm{NSs}$-based $\mathrm{Pb}$ (II) could be used for detection of $\mathrm{Pb}$ (II) in real water samples. 
Table S1 The parameters of MgO-based materials prepared in the present work.

\begin{tabular}{cccc}
\hline Samples & Surface area $\left(\mathrm{m}^{2} \cdot \mathrm{g}^{-1}\right)$ & Pore volume $\left(\mathrm{cm}^{3} \cdot \mathrm{g}^{-1}\right)$ & Pore size $(\mathrm{nm})$ \\
MgO-NSs & 158 & 0.25 & $2-3$ \\
MgO-NSs-0.9 & 59 & 0.19 & 2.7 \\
$\mathrm{MgO}-\mathrm{NSs}-2.7$ & 11 & 0.05 & 2.9 \\
$\mathrm{MgO}-\mathrm{NSs}-3.6$ & 18 & 0.10 & 3.6 \\
$\mathrm{MgO}-\mathrm{MPs}$ & 7 & 0.03 & $2.9-3.9$ \\
\hline
\end{tabular}


Table S2 Comparison of the sensing performances of MgO-NSs-based $\mathrm{Pb}(\mathrm{II})$ sensors fabricated in this work with the previously reported electrochemical $\mathrm{Pb}(\mathrm{II})$ sensors.

\begin{tabular}{|c|c|c|c|c|}
\hline & Sensitivity & & & \\
\hline materials & $\left(\mu \mathrm{A} \mu \mathrm{M}^{-1}\right)$ & linear range & LOD & Ref. \\
\hline $\mathrm{MgO}$ nanoflowers & 706 & $3.3 \mathrm{nM}-22 \mathrm{nM}$ & $2.1 \mathrm{pM}$ & 6 \\
\hline Graphene modified carbon nanosheets & 92.9 & $0.05 \mu \mathrm{M}-1 \mu \mathrm{M}$ & $1.12 \mathrm{nM}$ & 7 \\
\hline Hollow carbon nanospheres & 160 & $20 \mathrm{nM}-333 \mathrm{nM}$ & $0.60 \mathrm{nM}$ & 8 \\
\hline Nitrogen-doped microporous carbon & 1.9 & $6.1 \mathrm{nM}-122 \mathrm{nM}$ & $0.61 \mathrm{nM}$ & 9 \\
\hline Porous $\mathrm{Co}_{3} \mathrm{O}_{4}$ microspheres & 71.6 & $50 \mathrm{nM}-275 \mathrm{nM}$ & $18 \mathrm{nM}$ & 10 \\
\hline Nanosized hydroxyapatite/ionophore & 13.0 & $5.0 \mathrm{nM}-0.8 \mu \mathrm{M}$ & $1 \mathrm{nM}$ & 11 \\
\hline Ag nanoparticles & - & $10 \mathrm{pM}-0.3 \mathrm{nM}$ & $10 \mathrm{pM}$ & 12 \\
\hline Exfoliated graphite oxide & - & $1 \mathrm{pM}-0.1 \mu \mathrm{M}$ & $1 \mathrm{pM}$ & 13 \\
\hline $\mathrm{SnO}_{2} /$ reduced graphene oxide & 18.6 & $0.3 \mu \mathrm{M}-1.2 \mu \mathrm{M}$ & $0.18 \mathrm{nM}$ & 14 \\
\hline \multirow[t]{2}{*}{$\mathrm{MgO}-\mathrm{NSs}$} & 7.7 & $20 \mathrm{nM}-150 \mathrm{nM}$ & $0.16 \mathrm{nM}$ & This \\
\hline & & & & work \\
\hline
\end{tabular}

\section{Note 7:}

The present $\mathrm{MgO}-\mathrm{NSs}-$ based $\mathrm{Pb}(\mathrm{II})$ sensor exhibits the detection limit of $0.16 \mathrm{nM}$, which is lower than that of graphene modified carbon nanosheets $(1.12 \mathrm{nM}),{ }^{7}$ hollow carbon nanospheres $(0.60 \mathrm{nM}),{ }^{8}$ nitrogen-doped microporous carbon $(0.61 \mathrm{nM}),{ }^{9}$ porous $\mathrm{Co}_{3} \mathrm{O}_{4}$ microspheres $(18 \mathrm{nM}),{ }^{10}$ and nanosized hydroxyapatite/ionophore (1 $\mathrm{nM}) .{ }^{11}$ Although the detection limit of $\mathrm{Pb}(\mathrm{II})$ sensors based on $\mathrm{MgO}$ nanoflowers $(2.1$ $\mathrm{pM}),{ }^{6} \mathrm{Ag}$ nanoparticles $(10 \mathrm{pM}),{ }^{12}$ exfoliated graphite oxide $(1 \mathrm{pM}),{ }^{13}$ and S-23 
$\mathrm{SnO}_{2} /$ reduced graphene oxide $(0.18 \mathrm{nM})^{14}$ are lower than the $\mathrm{Pb}(\mathrm{II})$ sensor based on MgO-NSs in this work, these sensing materials also possess several disadvantages, including complicated synthesis processes, high cost, environmental unfriendly chemicals, and so on. Additionally, MgO-NSs-based $\mathrm{Pb}(\mathrm{II})$ sensor exhibits the linear range of $20 \mathrm{nM}$ to $150 \mathrm{nM}$, which is comparable to other reports. For example, our present sensor could be used to determine the $\mathrm{Pb}(\mathrm{II})$ with lower concentrations (20 $\mathrm{nM}-150 \mathrm{nM})$ than that of graphene modified carbon nanosheets $(0.05 \mu \mathrm{M}-1 \mu \mathrm{M}){ }^{7}$ porous $\mathrm{Co}_{3} \mathrm{O}_{4}$ microspheres $(50 \mathrm{nM}-275 \mathrm{nM}),{ }^{10}$ and $\mathrm{SnO}_{2} /$ reduced graphene oxide $(0.3 \mu \mathrm{M}-1.2 \mu \mathrm{M}) .{ }^{14}$ Unfortunately, a relatively low sensitivity was obtained for the MgO-NSs-based $\mathrm{Pb}$ (II) sensor, compared to the previously reported electrochemcial $\mathrm{Pb}(\mathrm{II})$ sensors (Table S2). Thus, the enhanced sensitivity is the primarity mission for the future work for the $\mathrm{MgO}-\mathrm{NSs}-$ based $\mathrm{Pb}(\mathrm{II})$ sensor.

\section{Note 8:}

Furthermore, novelty and advances of the present work was also discussed from two aspects compared to the previously reported publications: the preparation of sensing materials and the sensing performances. To date, several strategies have been developed to prepare MgO-based materials with different structures. For example, precipitation-aging calcination method, ${ }^{15}$ calcination of magnesium carbonate hydrates, ${ }^{16}$ hydrothermal and calcination method without surfactant, ${ }^{17,18}$ wet-chemical method assisted by sodium silicate, ${ }^{6}$ have been successfully developed for preparation of MgO-based materials with different morphologies. However, most of these materials are typical non-porous structure. Additionally, mesoporous MgO-based 
materials have been also synthesized by hydrothermal and calcination method using magnesium powder as precursor, ${ }^{19}$ evaporation induced self-assembling (EISA) templated by tri-block copolymer, ${ }^{20}$ hard-templating pathway, ${ }^{21}$ templated by $\mathrm{SiO}_{2}$ nanoparticles. ${ }^{22}$ Unfortunately, these methods display obvious shortcomings, such as, rigorous and complicated experimental conditions, low product-yield, and so on.

\section{References:}

[1] Wei, Y.; Jin, D.; Ding, T.; Shih, W.-H.; Liu, X.; Cheng, S. Z. D.; Fu, Q. A Non-surfactant Templating Route to Mesoporous Silica Materials, Adv. Mater. 1998, 3, 313-316.

[2] Wei, Y.; X. J.; Dong, H.; Dong J. H.; Qiu, K.; Jansen-Varnum, S. A. Preparation and Physisorption Characterization of d-Glucose-Templated Mesoporous Silica Sol-Gel Materials, Chem. Mater. 1999, 11, 2023-2029.

[3] Feng, R.; Hu, X.; Yan, X.; Yan, Z.; Rood, M. J. A High Surface Area Mesoporous Gamma- $\mathrm{Al}_{2} \mathrm{O}_{3}$ with Tailoring Texture by Glucose Template for Ethanol Dehydration to Ethylene, Micropor. Mesopor. Mater. 2017, 241, 89-97.

[4] Yu, X.-Y.; Luo, T.; Jia, Y.; Zhang, Y.-X.; Liu, J.-H.; Huang, X.-J. Porous Hierarchically Micro-/Nanostructured MgO: Morphology Control and Their Excellent Performance in As(III) and As(V) Removal, J. Phys. Chem. C 2011, $115,22242-22250$.

[5] Liu, W.-J.; Jiang, H.; Ding, Y.-W.; Yu, H.-Q. Mesoporous Carbon Stabilized $\mathrm{MgO}$ Nanoparticles Synthesized by Pyrolysis of $\mathrm{MgCl}_{2}$ Preloaded Waste Biomass for Highly Efficient $\mathrm{CO}_{2}$ Capture, Environ. Sci. Technol., 2013, 47, 
9397-9403.

[6] Wei, Y.; Yang, R.; Yu, X.; Wang, L.; Liu, J.; Jiang, X. Stripping Voltammetry Study of Ultra-trace Toxic Metal Ions on Highly Selectively Adsorptive Porous Magnesium Oxide Nanoflowers, Analyst 2012, 137, 2183-2191.

[7] Zhang, J.; Jin, Z.; Li, W.; Dong, W.; Lu, A. Graphene Modified Carbon Nanosheets for Electrochemical Detection of $\mathrm{Pb}(\mathrm{II})$ in Water, J. Mater. Chem. A 2013, $1,13139-13145$.

[8] Zhang, L.; Li, W.; Yan, D.; Wang, H.; Lu, A. Size Dependent Electrochemical Detection of Trace Heavy Metal Ions Based on Nano-patterned Carbon Sphere Electrodes, Nanoscale 2016, 8, 13695-13700.

[9] Xiao, L.; Xu, H.; Zhou, S.; Song, T.; Wang, H.; Li, S.; Gan, W.; Yuan, Q. Simultaneous Detection of $\mathrm{Cd}(\mathrm{II})$ and $\mathrm{Pb}(\mathrm{II})$ by Differential Pulse Anodic Stripping Voltammetry at A Nitrogen-doped Microporous Carbon/Nafion/bismuth-film Electrode, Electrochim. Acta 2014, 143, 143-151.

[10]Liu, Z.; Chen, X.; Zhang, Y.; Wang, L.; Huang, X. Well-arranged Prous $\mathrm{Co}_{3} \mathrm{O}_{4}$ Microsheets for Electrochemistry of $\mathrm{Pb}(\mathrm{II})$ Revealed by Stripping Voltammetry, Electron. Commun. 2013, 30, 59-62.

[11]Pan, D.; Wang, Y.; Chen, Z.; Lou, T.; Qin, W. Nanomaterial/Ionophore-Based Electrode for Anodic Stripping Voltammetric Determination of Lead: An Electrochemical Sensing Platform toward Heavy Metals, Anal. Chem. 2009, 81, 5088-5094.

[12] Sivasubramanian, R.; Sangaranarayanan, M. V. Detection of Lead Ions in 
Picomolar Concentration Range using Underpotential Deposition on Silver Nanoparticles-deposited Glassy Carbon Electrodes, Talanta 2011, 85, 2142-2147.

[13]Ramesha, G. K.; Sampath, S. Exfoliated Graphite Oxide Modified Electrode for the Selective Determination of Picomolar Concentration of Lead, Electroanalys. 2007, 23, 2472-2478.

[14]Wei, Y.; Gao, C.; Meng, F.; Li, H.; Wang, J.; Liu, J.; Huang, X. $\mathrm{SnO}_{2} /$ Reduced Graphene Oxide Nanocomposite for the Simultaneous Electrochemical Detection of Cadmium(II), Lead(II), Copper(II), and Mercury(II): An Interesting Favorable Mutual Interference, J. Phys. Chem. C 2012, 116, 1034-1041.

[15]Purwajanti, S.; Zhou, L.; Nor, Y. A.; Zhang, J.; Zhang, H.; Huang, X.; Yu, C. Synthesis of Magnesium Oxide Hierarchical Microspheres: A Dual-functional Material for Water Remediation, ACS Appl. Mater. Interfaces 2015, 7, 21278-21286.

[16] Sutradhar, N.; Sinhamahapatra, A.; Pahari, S. K.; Pal, P.; Bajaj, H. C.; Mukhopadhyay, I.; Panda, A. B. Controlled Synthesis of Different Morphologies of $\mathrm{MgO}$ and Their Use as Solid Base Catalysts, J. Phys. Chem. C 2011, 115, 12308-12316.

[17]Cao, C.; Qu, J.; Wei, F.; Liu, H.; Song, W. Superb Adsorption Capacity and Mechanism of Flowerlike Magnesium Oxide Nanostructures for Lead and Cadmium Ions, ACS Appl. Mater. Interfaces 2012, 4, 4283-4287.

[18]Feng, J.; Liu, S.; Chen, T.; Ren, Y.; Lv, Y.; Fan, Z. Fabrication of MgO Nanosheets for Removal of Ni(II) via Hydrothermal and Calcination Method 
Without Surfactant, Mater. Chem. Phys. 2016, 183, 499-505.

[19]Feng, J.; Gao, M.; Zhang, Z.; Liu, S.; Zhao, X.; Ren, Y.; Lv, Y.; Fan, Z. Fabrication of Mesoporous Magnesium Oxide Nanosheets Using Magnesium Powder and Their Excellent Adsorption of Ni(II), J. Colloid interf. Sci. 2018, 510, $69-76$.

[20]Eckharadt, B.; Ortel, E.; Polte, J.; Bernsmeier, D.; Görke, O.; Strasser, P.; Kraehnert, R. Micelle-Templated Mesoporous Films of Magnesium Carbonate and Magnesium Oxide, Adv. Mater. 2012, 24, 3115-3119.

[21]Li, W.-C.; Lu, A.-H.; Weidenthaler, C.; Schüch, Hard-Templating Pathway To Create Mesoporous Magnesium Oxide, Chem. Mater. 2004, 16, 5676-5681.

[22]Yang, S.; Huang, P.; Peng, L.; Cao, C.; Zhu, Y.; Wei, F.; Sun, Y.; Song, W. Hierarchical Flowerlike Magnesium Oxide Hollow Spheres With Extremely High Surface Area for Adsorption and Catalysis, J. Mater. Chem. A 2016, 4, 400-406. 